\title{
Urine albumin to creatinine ratio-response to exercise in diabetes
}

\author{
I G JEFFERSON, S A GREENE, M A SMITH, R F SMITH, N K G GRIFFIN, AND \\ J D BAUM
}

Children's Diabetes Centre, University Department of Paediatrics, and Sheikh Rashid Diabetes Unit, Radcliffe Infirmary, Oxford and Northampton General Hospital

SUMMARY Albuminuria was studied in 40 diabetic children before and after a standardised exercise test, and also in 21 normal children; the results are expressed as geometric mean $(95 \%$ range) of urine albumin:urine creatinine ratio $(\mathrm{mg} / \mathrm{mg})$. There was no significant difference between the mean resting albumin:creatinine ratio in the two groups, or between these ratios before and after exercise in the normal children. In the diabetic children, however, the mean urine albumin:creatinine ratio after exercise was significantly higher than both the value before exercise and the postexercise value of the normal children, with 10 of 40 diabetic children showing a value after exercise greater than the $95 \%$ range of the geometric mean of the control group.

The diabetic children were also studied by random urine albumin:creatinine ratios and split (erect:supine) 24 hour urine collection; none was abnormal.

Although renal microvascular complications of diabetes are rarely seen in childhood, early morphological changes are visible on renal biopsy within a few years of onset in virtually all patients $;^{1}$ and yet only 30 to $35 \%$ will progress to clinical diabetic nephropathy. ${ }^{2}$ In this $35 \%$ there is a variable 'silent' period, during which, although there is histological evidence of advancing nephropathy, proteinuria is not detectable by standard clinical methods using a reagent strip (Albustix, Ames), and once overt proteinuria is established there is a relentless fall in glomerular filtration rate towards end stage renal failure within a few years. ${ }^{13}$

Several studies, mainly in adults, have shown that before the onset of overt proteinuria, many diabetics have a higher mean urinary albumin excretion rate than normal subjects, and that this early 'microalbuminuria' is at least partially correctable by strict metabolic control. ${ }^{4}$ Other studies have delineated low and high risk groups for the development of diabetic nephropathy on the basis of overnight albumin excretion rates before the onset of overt proteinuria. ${ }^{5}$

Exercise increases urinary albumin excretion. During exercise it seems likely that the glomerulus becomes leaky when a higher filtration pressure operates. If the membrane is already abnormal or stressed in some way the increased leak will occur at a lower threshold and to a more noticeable degree. Thus it may be possible to identify a subgroup within the diabetic population at particular risk of developing diabetic nephropathy at the early stage of slightly raised albumin excretion using exercise as a probe to unmask latent glomerular damage.

Previous studies have been mainly in adults and have involved the use of albumin clearance or excretion rates; $;^{6-9}$ these studies are difficult to perform in children because of the problems of collection of accurately timed and measured volumes of urine.

The use of the urine albumin: urine creatinine ratio minimises the errors due to variations in the glomerular filtration rate and has been shown to be a useful measure of overall glomerular permeability, ${ }^{10}$ although it does not take account of nephron hyperfiltration or tubular reabsorption. The albumin:creatinine ratio on random specimens has been shown to correlate well with the albumin excretion rate $^{1011}$ and has the advantage of not requiring timed and measured urine collection.

In this pilot study the urine volumes and collection times for diabetic children were noted and blood samples were taken before the start of exercise to allow comparison between the albumin: 
creatinine ratio and albuinin excretion rate, and between creatinine clearance before and after exercise.

\section{Patients and methods}

Forty children (16 boys and 24 girls) with insulin dependent diabetes were chosen from a total clinic population of 70 , selected within the age range of 8 to 16 years so as to be able to use the bicycle ergometer. Their clinical characteristics, shown as mean and range, were: age $12.6(8.3$ to 15.6$)$ years, duration of diabetes $3.9(0.2$ to 11.9$)$ years, height 167 (124 to 182$) \mathrm{cm}$, weight $49 \cdot 6$ (23 to 71$) \mathrm{kg}$, glycosylated haemoglobin $12.4(6.2$ to 17.5$) \%$.

None had a history of urinary tract infection, all had normal blood pressure, and all had consistently negative results for urinary protein when the samples were tested with Albustix. At the time of testing all had sterile urine and normal urine microscopy. None of the postpubertal girls was menstruating at or around the time of the test.

Twenty one normal children from local schools were used as controls for the exercise test: 11 boys and 10 girls, age $13.6(12.0$ to 15.3$)$ years, height 161 (137 to 169) $\mathrm{cm}$, and weight 51.7 (39 to 70$) \mathrm{kg}$.

Both normal and diabetic subjects performed a standardised exercise test on a bicycle ergometer. Each child was asked to empty the bladder on arrival; a random urine sample and midstream sample of urine were obtained. The child then spent one hour at rest (sitting) before emptying the bladder to provide the pre-exercise urine sample and then performed a 15 minute period of exercise on the bicycle ergometer at 2 watts $/ \mathrm{kg}$ body weight, followed by a further 45 minutes sitting at rest, at the end of which a final urine sample was collected.

The urine samples were assayed for albumin using a double antibody radioimmunoassay, ${ }^{12}$ and for creatinine by standard picric acid autoanalyser technique (SMA 1260). Blood was assayed for creatinine, albumin, and glycosylated haemoglobin (Corning).

In addition, the diabetic group was also studied with multiple random urine samples collected on clinic visits and a timed 24 hour urine collection split into daytime (erect) and overnight (supine) samples collected during the 24 hours before the exercise test.

Data on albumin excretion expressed as the albumin excretion rate or albumin:creatinine ratio were not normally distributed and have been log transformed to achieve a Gaussian distribution for statistical analysis. The geometric means and $95 \%$ range limits quoted are derived from the antilog of the mean of the transformed data and twice its standard deviation. Data on creatinine clearance expressed as $\mathrm{ml} /$ minute per $1.73 \mathrm{~m}^{2}$ were normally distributed and are quoted as arithmetic mean (SD). Statistical analysis has been carried out using paired and Student's $t$ tests and correlation coefficients.

Ethical permission for the study was obtained from the Northampton General Hospital Ethical Committee.

\section{Results}

Exercise test. There was no significant difference between the mean pre-exercise albumin:creatinine ratio for the diabetic and the control groups, and no significant difference between the mean albumin: creatinine ratios before and after exercise in the control group (Table 1). The diabetic children showed a significantly higher mean ratio after exercise, however, compared with both their preexercise values $(\mathrm{P}<0.0001)$ and the post-exercise value for control children $(\mathrm{P}<0 \cdot 004)$. The untransformed urinary albumin:creatinine ratios for individual children are shown in the Figure.

Most of the diabetic children did not show an increase in the urinary albumin:creatinine ratio with the stress of exercise, but some seemed to show an increase after exercise which was not seen in the control group. Ten of 40 children with diabetes had an increase in this ratio after exercise greater than the $95 \%$ range for the control group.

Table 1 Urinary albumin:creatinine (UA/UC) and albumin excreticn rate (AER) values (geometric mean (95\% range) and creatinine clearance (mean (SD)) for diabetic and control children before and after exercise

\begin{tabular}{|c|c|c|}
\hline & $\begin{array}{l}\text { Control children } \\
(n=21)\end{array}$ & $\begin{array}{l}\text { Diabetic } \\
\text { children } \\
(n=40)\end{array}$ \\
\hline $\begin{array}{l}\text { UA/UC before exercise } \\
\text { (mg/mg) }\end{array}$ & $\begin{array}{l}0.011 \quad \leftarrow \text { NS } \rightarrow \\
\begin{array}{l}\uparrow \\
\text { NS } \\
\downarrow\end{array}\end{array}$ & $\begin{array}{l}0 \cdot 009 \\
(0 \cdot 003-0 \cdot 032) \\
\quad \uparrow \\
\mathrm{P}<0 \cdot 0001 \\
\quad \downarrow\end{array}$ \\
\hline $\begin{array}{l}\text { UA/UC after exercise } \\
\text { (mg/mg) }\end{array}$ & $\begin{array}{l}0.009 \\
(0.003-0.027) \leftarrow \mathrm{P}<0.004\end{array}$ & $\begin{array}{l}0 \cdot 016 \\
(0 \cdot 003-0 \cdot 089)\end{array}$ \\
\hline $\begin{array}{l}\text { AER before exercise } \\
(\mu \mathrm{g} / \mathrm{min})\end{array}$ & - & $\begin{array}{l}5 \cdot 55 \\
(1 \cdot 38-22 \cdot 25) \\
\uparrow \\
P<0 \cdot(0) 1 \\
\downarrow\end{array}$ \\
\hline $\begin{array}{l}\text { AER after exercise } \\
(\mu \mathrm{g} / \mathrm{min})\end{array}$ & - & $\begin{array}{l}9 \cdot 51 \\
(0 \cdot 98-63 \cdot 36)\end{array}$ \\
\hline $\begin{array}{l}\text { Creatinine clearance before } \\
\text { exercise }(\mathrm{ml} / \mathrm{min} \text { per } \\
\left.1.73 \mathrm{~m}^{2}\right)\end{array}$ & - & $\begin{array}{c}110 \\
\uparrow \\
\text { NS } \\
\downarrow\end{array}$ \\
\hline $\begin{array}{l}\text { Creatinine clearance after } \\
\text { exercise }(\mathrm{ml} / \mathrm{min} \text { per } \\
\left.1.73 \mathrm{~m}^{2}\right)\end{array}$ & - & $109(28)$ \\
\hline
\end{tabular}




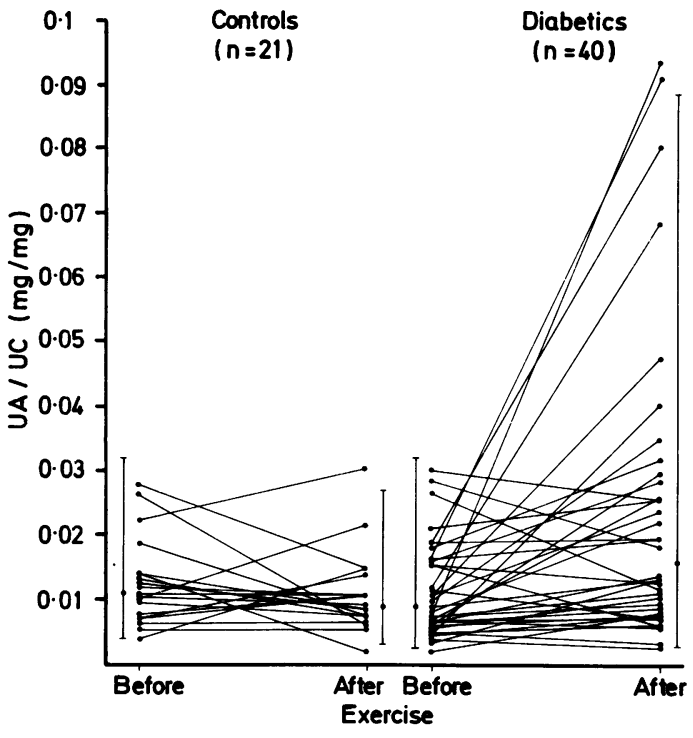

Figure Urine albumin:urine creatinine ratio (UA/UC) before and after exercise for control children $(n=21)$ and children with diabetes $(n=40)$. The geometric mean and $95 \%$ range for each group is shown.

There is close correlation between values for the albumin excretion rate and the urinary albumin: creatinine ratio both before $(\mathrm{r}=0.79, \mathrm{P}<0.0001)$ and after exercise $(\mathrm{r}=0.92, \quad \mathrm{P}<0.0001)$, and similar results are found using the albumin clearance or albumin excretion rate rather than the albumin: creatinine ratio as the measure of albuminuria.

The increase in albuminuria is not accounted for by a change in creatinine clearance as there was no significant difference between the clearances before and after exercise in the group as a whole (before exercise $110(28) \mathrm{ml} /$ minute per $1.73 \mathrm{~m}^{2}$; after exercise $109(28) \mathrm{ml} /$ minute per $1.73 \mathrm{~m}^{2}$ ) nor in the subgroup with a high albumin:creatinine ratio after exercise (before exercise 104 (26) $\mathrm{ml} /$ minute per $1.73 \mathrm{~m}^{2}$; after exercise 102 (29) $\mathrm{ml} /$ minute per $1.73 \mathrm{~m}^{2}$ ).

Random urinary albumin:creatinine ratio. Each child with diabetes had random urine samples collected at various clinic visits (mean number of samples per patient 4.5 ; range 1 to 9 ). Most of the random urinary albumin:creatinine values for the diabetic children fell within the ranges established in our normal group, both at rest and after exercise $(0.003$ to 0.032$)$. Eight of the diabetic children, three of whom had raised albumin:creatinine values after exercise, showed a single random ratio above the range of our normal group. There was wide variation in random urinary albumin:creatinine values within individual patients, and the mean random ratio for those who responded abnormally to exercise did not differ significantly from that of the rest of the group.

Split 24 hour urine samples. Each diabetic patient collected a timed 24 hour urine sample before the exercise test, split into daytime (erect) and overnight (supine) samples.

All 40 children with diabetes had normal serum creatinine concentrations and would be expected to have normal or high creatinine clearance at this stage of the disease. Creatinine clearance values of less than $60 \mathrm{ml} /$ minute per $1.73 \mathrm{~m}^{2}$ were, however, calculated on five overnight and three daytime collections, and seven patients showed a variation of greater than $50 \%$ between overnight and daytime values. Combining these factors a minimum of eight of 40 of the 24 hour collections were thought to be inaccurate due to collection errors. Although this inaccuracy affects calculation of creatinine clearance and the albumin excretion rate, the urinary albumin: creatinine value should be relatively unaffected. The eight inaccurate collections have been omitted from calculations and correlations of creatinine clearance and albumin excretion rate.

There was close correlation between urinary albumin:creatinine and albumin excretion rate values on both erect $(r=0.881, P<0.0001)$ and supine collections of urine $(r=0.832, P<0.0001)$. Although there was a trend towards lower albumin excretion in overnight compared with daytime specimens as measured by the urinary albumin: creatinine ratio and the albumin excretion rate, this did not reach significance in the group as a whole or in the two subgroups of normal and abnormal responders to exercise (Table 2).

Comparing split 24 hour urine data in the subgroup of patients with a high urinary albumin: creatinine ratio after exercise (greater than 0.027 ) with values of patients with a normal ratio after exercise, there was no difference between the two groups for values of erect or supine creatinine clearance or supine urinary albumin:creatinine and albumin excretion rate values. Values of erect albuminuria showed a trend to be higher in the subgroup with a high albumin:creatinine ratio after exercise; reaching significance expressed as erect albumin excretion rate $(\mathrm{P}<0.02)$ but just failing to reach this when expressed as erect albumin:creatinine $(P=0 \cdot 051)$

There was no significant difference in creatinine clearance, between either erect and supine samples or between the subgroups. 
Table 2 Erect (daytime) and supine (overnight) urinary albumin:creatinine $(U A / U C)$ and albumin excretion rate (AER) (geometric mean ( $95 \%$ range)) and creatinine clearance (mean (SD)) for all diabetic group and for subgroups with high or normal UA/UC after exercise

\begin{tabular}{|c|c|c|c|c|}
\hline & & $\begin{array}{l}U A / U C \\
(m g / m g)\end{array}$ & $\begin{array}{l}A E R \\
(\mu g / \min )\end{array}$ & $\begin{array}{l}\text { Creatinine } \\
\text { clearance } \\
(\mathrm{ml} / \mathrm{min} \text { per } \\
\left.1.73 \mathrm{~m}^{2}\right)\end{array}$ \\
\hline & Erect & $\begin{array}{l}0 \cdot 009 \\
(0.002-0.045)\end{array}$ & $\begin{array}{l}5 \cdot 47 \\
(1 \cdot 00-29 \cdot 79)\end{array}$ & $109(26)$ \\
\hline \multirow[t]{2}{*}{ All diabetic children } & & NS & NS & NS \\
\hline & Supine & $\begin{array}{l}0.008 \\
(0.003-0.025)\end{array}$ & $\begin{array}{l}4 \cdot 55 \\
(1 \cdot 17-17 \cdot 71)\end{array}$ & $109(23)$ \\
\hline \multirow{2}{*}{$\begin{array}{l}\text { Patients with } \\
\text { UA/UC }>0.027 \\
\mathrm{mg} / \mathrm{mg} \text { after } \\
\text { exercise }\end{array}$} & & $\begin{array}{l}0 \cdot 016 \\
(0 \cdot 002-0 \cdot 11)\end{array}$ & $\begin{array}{l}10 \cdot 9 \\
(1 \cdot 2-101 \cdot 6)\end{array}$ & $105(29)$ \\
\hline & Erect & NS & $\mathrm{P}<0.02$ & NS \\
\hline $\begin{array}{l}\text { Patients with } \\
\text { UA/UC<0.027 } \\
\text { mg/mg after } \\
\text { exercise }\end{array}$ & & $\begin{array}{l}0.008 \\
(0.002-0.029)\end{array}$ & $\begin{array}{l}4 \cdot 2 \\
(1 \cdot 4-12 \cdot 2)\end{array}$ & $111(25)$ \\
\hline \multirow{2}{*}{$\begin{array}{l}\text { Patients with } \\
\text { UA/UC }>0.027 \\
\mathrm{mg} / \mathrm{mg} \text { after } \\
\text { exercise }\end{array}$} & & $\begin{array}{l}0.009 \\
(0.002-0.044)\end{array}$ & $\begin{array}{l}6.9 \\
(1.4-11 \cdot 7)\end{array}$ & $109(23)$ \\
\hline & Supine & NS & NS & NS \\
\hline $\begin{array}{l}\text { Patients with } \\
\text { UA/UC }<0.027 \\
\text { mg/mg after } \\
\text { exercise }\end{array}$ & & $\begin{array}{l}0 \cdot 008 \\
(0 \cdot 003-0 \cdot 020)\end{array}$ & $\begin{array}{l}3 \cdot 9 \\
(1 \cdot 2-12 \cdot 0)\end{array}$ & $110(23)$ \\
\hline
\end{tabular}

There was no correlation between albumin:creatinine or albumin excretion rate for erect specimens and patient age, duration of diabetes, or glycosylated haemoglobin. Similarly, there was no correlation between the albumin:creatinine ratio or the albumin excretion rate on supine specimens and duration of diabetes or glycosylated haemoglobin. There was, however, a slight correlation between supine albumin excretion rate and patient age $(r=0.373 ; P<0.05)$; supine albumin:creatinine ratio failed to reach significance.

\section{Discussion}

A proportion of the diabetic children studied showed an increase in urinary albumin excretion after exercise which was not seen in the control group. The diabetic children all had a resting urinary albumin:creatinine ratio within the normal range but in $\mathbf{1 0}$ of $\mathbf{4 0}$ the ratio after exercise was greater than the $95 \%$ range of the normal geometric mean $(0.027 \mathrm{mg} / \mathrm{mg})$ established by the control group.

None of these 10 children would have been consistently identifiable on random urinary albumin measurement and none would have been categorised as abnormal on 24 hour or overnight urine albumin excretion. ${ }^{13}$ There was no significant difference between the two groups of diabetic children with high or normal ratios after exercise in terms of duration of disease (mean (SD), 5.6 (3.7) years $v 4.7$ (3.2) years respectively or glycosylated haemoglobin $(11.9(2.6) \% \vee 11.2(2.3) \%$ respectively).

The group with a high urinary albumin:creatinine ratio was slightly older (mean (SD), 13.8 (1.6) years $v 12.2(1.8)$ years; $\mathrm{P}<0.02$ ), seven were girls (five postpubertal) and three were boys (all postpubertal). The slight excess of girls in the abnormal group (original sex ratio of group 1.5:1) raises the possibility of contamination by vaginal secretion of post exercise samples in postpubertal subjects, but the increase was not seen in postpubertal control girls and the albumin specific assay should minimise this error.

A previous study of albuminuria in a population of normal children has shown higher albumin excretion in girls than boys, and in daytime urine than in overnight urine. ${ }^{13}$ A slight increase in albuminuria with age was shown if expressed as the albumin excretion rate but not as the albumin: creatinine ratio, although the authors also found good correlation between these two values.

Studies in adult patients have shown an increased mortality and morbidity in diabetic patients with an overnight albumin excretion rate above $30 \mu \mathrm{g} /$ minute. ${ }^{5}$ All oưr patients had an overnight albumin excretion of less than $30 \mu \mathrm{g} /$ minute and only tour had an overnight rate greater than $7 \mu \mathrm{g} /$ minute (above the $95 \%$ range established in normal children range), ${ }^{13}$ three of whom also had a high urinary albumin:creatinine ratio after exercise.

Improved blood glucose control by the use of continuous subcutaneous insulin infusion has been shown to correct exercise induced albuminuria in adults. ${ }^{9}$ The use of the albumin:creatinine ratio and an exercise stress test to unmask latent glomerular disease provides an easily performed outpatient test for diabetic patients that may serve to identify those children at particular risk of developing overt diabetic nephropathy, and thereby allow intervention at a stage when these early changes may be reversible by strict metabolic control. The relevance of these findings will, however, only be apparent after long term follow up.

\footnotetext{
Grateful thanks are due to Hannah Dhar for the laboratory estimations of urinary albumin and to Belinda Moss for preparation of the manuscript.

\section{References}

1 Osterby R. Early phases in the development of diabetic glomerulopathy. Acta Med Scand [Suppl] 1975;574:1-80.
} 
2 Deckert T, Poulsen JE, Larsen M. Prognosis of diabetics with diabetes onset before the age of thirty-one: I: survival, causes of death and complications. Diabetologia 1978:14:363-70.

${ }^{3}$ Mogensen CE. Early functional and morphologic vascular renal consequences of the diabetic state. Diabetologia 1979;17:71-6.

${ }^{4}$ Steno Study Group. Effect of 6 months of strict metabolic control on eye and kidney function in insulin dependent diabetics with background retinopathy. Lancet 1982;i:121-4.

5 Viberti GC, Jarrett RJ, Mahmud U, Hill RD, Argyropoulos A, Keen $\mathbf{H}$. Microalbuminuria as a predictor of clinical nephropathy in insulin dependent diabetes mellitus. Lancet 1982;i: 1430-2.

${ }^{6}$ Mogensen CE, Vittinghas E. Urinary albumin excretion during exercise in juvenile diabetes: a provocation test for early abnormalities. Scand J Clin Lab Invest 1975;35:295-300.

7 Viberti GC, Jarrett RJ, McCartney M, Keen H. Increased glomerular permeability to albumin induced by exercise in diabetic subjects. Diabetologia 1978;14:293-300.

${ }^{8}$ Huttunen N-P, Kaar M-L, Puukar R, Akerblom HK. Exercise induced proteinuria in children and adolescents with type 1 (insulin dependent) diabetes. Diabetologia 1981;21:495-7.

${ }^{9}$ Koivisto VA, Huttunen N-P, Vierikko P. Continuous subcutaneous insulin infusion corrects exercise induced albuminuria in juvenile diabetes. $\mathrm{Br}$ Med $J$ 1981;282:778-9.

${ }^{10}$ Barratt TM, McLaine PN, Soothill JF. Albumin excretion as a measure of glomerular dysfunction in children. Arch Dis Child 1970;45:496-501.

1 Houser M. Assessment of proteinuria using random urine samples. J Pediatr 1984;104:845-8.

12 Woo J, Floyd M, Cannon DC, Kahan B. Radioimmunoassay for urinary albumin. Clin Chem 1978;24(a):1464-7.

13 Davies AG, Postlethwaite RJ, Price DA, Burn LJ, Houlton CA, Fielding BA. Urinary albumin excretion in school children. Arch Dis Child 1984;59:625-30.

Correspondence to Dr I G Jefferson, Department of Paediatrics, John Radcliffe Hospital, Oxford OX3 9DU.

Received 11 December 1984

\section{Commentary}

\section{MATTI VEHASKARI}

\section{Washington University School of Medicine, St Louis, USA}

Paediatricians may not always be aware that nearly half of all diabetic children will eventually develop diabetic nephropathy. Once present, it defies all treatment progressing almost without exception to end stage renal disease. Diabetic nephropathy is rarely seen in paediatric practice because the first clinical sign of it, proteinuria, is not evident until the duration of juvenile diabetes mellitus exceeds 10 years.

The issue of diabetic nephropathy is, however, brought much closer to those caring for diabetic children by the recent findings indicating tha subtle renal functional changes may be present from the very onset of diabetes. In adult diabetics, the presence of two early abnormalities seems well established. Firstly, there is an increase in the glomerular filtration rate. Since the total number of glomeruli does not increase, some or all glomeruli must be hyperfiltrating. Secondly, although the urinary total protein excretion may be within normal limits, small increases in albumin excretion can often be documented. This 'microalbuminuria' has been shown to occur in some patients only with physical exercise, while in others even the baseline albumin excretion is slightly increased.

Two reports in this issue of the Archives extend these observations to the paediatric age range. Davies et al show that approximately one half of their diabetic children had increased glomerular filtration rates and that resting urinary albumin excretion was increased in 13 of the 83 subjects. In contrast, Jefferson et al were unable to confirm the increase in baseline albumin excretion in their smaller group of children, but they showed an abnormally high excretion in response to controlled exercise in 10 of 40 children.

Based mainly on experimental work, a tentative hypothesis has been put forward to explain the development of diabetic nephropathy. According to the hypothesis, hyperglycaemia or some other aspect of the metabolic disorder leads initially, perhaps via a hormonal mediator, to intrarenal haemodynamic changes and hence to an increased glomerular filtration rate. The accompanying increase in albumin excretion may result from the same haemodynamic changes. At a single nephron level, longstanding hyperfiltration is detrimental to the glomeruli, leading to gradual glomerular sclerosis and destruction; the onset of this phase is marked by the appearance of clinical nephropathy with heavy proteinuria followed by a steady decline in renal function.

The hypothesis immediately raises two important questions regarding the clinical studies. Are the patients with the subtle abnormalities the same ones who later develop diabetic nephropathy? And if so, can the progression be prevented by early intervention, for example by strict metabolic control or other manoeuvre that might abate the hyperfiltration? Preliminary data on adult diabetics suggest that resting microalbuminuria is indeed a predictor of diabetic nephropathy: similar information on exercise induced microalbuminuria is not available. Short term treatment with continuous subcutaneous insulin infusion brings both resting and exercise induced microalbuminuria towards normal, but the proof that this has anything to do with successful prevention of diabetic nephropathy must await the results of long term intervention studies. Whether the supranormal glomerular filtration rate is decreased by switching from conventional insulin treatment to continuous infusion is not clear. 